\title{
Transcatheter Aortic Valve Implantation for Degenerated 19-mm Aortic Bioprosthetic Valve
}

\author{
Kizuku Yamashita, MD; Tomoyuki Fujita, MD, PhD; Satsuki Fukushima, MD, PhD; \\ Yusuke Shimahara, MD; Yuta Kume, MD; Yorihiko Matsumoto, MD; Naonori Kawamoto, MD; \\ Tatsuro Hitsumoto, MD; Nobuyasu Ito, MD; Yasuhiro Hamatani, MD; Atsushi Okada, MD; \\ Hiroyuki Takahama, MD, PhD; Makoto Amaki, MD, PhD; Takuya Hasegawa, MD, PhD; \\ Yasuo Sugano, MD, PhD; Hideaki Kanzaki, MD, PhD; Toshihisa Anzai, MD, PhD; \\ Satoshi Yasuda, MD, PhD; Junjiro Kobayashi, MD, PhD
}

Background: The valve-in-valve procedure, in which a transcatheter heart valve (THV) is implanted over a prosthetic valve, has been shown to be safe and therapeutically effective, depending on the size of the replacement valve.

Methods and Results: We report 3 cases of successful valve-in-valve procedure to replace a degenerated 19-mm stented prosthetic aortic valve. Balloon-expanding THVs were implanted: $20-\mathrm{mm}$ in the 1 st case and 23-mm in the next 2. Aortic stenosis was almost completely resolved in all patients, who recovered promptly and without cardiac adverse events.

Conclusions: Using the valve-in-valve procedure for a 19-mm degenerated bioprosthesis was feasible and safe.

Key Words: Degenerated bioprosthesis; Transcatheter aortic valve implantation; Valve-in-valve

A lthough redo valve replacement is the standard intervention for a degenerated aortic bioprosthetic valve, 1,2 mortality associated with repeat valve replacement has been reported as $11-32 \%$ in selected highrisk patients. ${ }^{3,4}$ Transcatheter aortic valve replacement for a degenerated aortic bioprosthetic valve, also known as a "valve-in-valve" procedure, has been reported by the global Valve-in-Valve International Data (VIVID) Registry as safe and effective. ${ }^{5}$ In that report, Dvir et al showed that a small implanted surgical valve (labeled size $\leq 21 \mathrm{~mm}$ ) was an independent risk factor for 1-year mortality after valve-invalve. Importantly, valve-in-valve mortality associated with the 19 -mm surgical valve was $2.4 \%$ in the VIVID Registry, although in Japan, the 19-mm surgical valve is used in 18.7$49.8 \%$ of all aortic valve replacement procedures. ${ }^{6,7}$ The VIVID Registry report therefore suggested that, although valve-in-valve for a small-sized bioprosthetic valve is challenging, it is clinically necessary for Japanese patients. We report the first 3 clinical cases of valve-in-valve in patients with a degenerated 19-mm aortic bioprosthesis.

\section{Methods}

The National Cerebral and Cardiovascular Center Institutional Review Board approved the study (UMIN000026450), a prospective, interventional cohort study with off-label use of a commercially available transcatheter heart valve (THV) in Japan for a degenerated bioprosthesis. The primary endpoint was safety and therapeutic efficacy within 30 days, based on Valve Academic Research Consortium-2. ${ }^{8}$ Between December 2016 and March 2017, 3 patients with a $19-\mathrm{mm}$ bioprosthesis underwent valve-in-valve with a SAPIEN XT Transcatheter Heart Valve (Edwards Lifesciences, Irvine, CA, USA). Baseline demographics and clinical outcomes are shown in the Table. Deployment was performed with nominal volume, and pre- or post-dilatation was not performed. Standard transthoracic echocardiography was used to assess heart and valve function at baseline and on postoperative day 5 .

\section{Patient 1}

An 82-year-old woman presented with progressive congestive cardiac failure caused by structural valve deterioration (SVD) of a 19-mm Carpentier-Edwards PERIMOUNT Aortic Heart Valve implanted 12 years earlier. Echocardiography showed a severely stenotic aortic valve with global thickening and partial calcification of all 3 leaflets. Surgical redo replacement was deferred because of a "porcelain" aorta, but a 20-mm SAPIEN XT (Edwards Lifesciences) was successfully implanted over the previously implanted

Received August 10, 2017; revised manuscript received October 4, 2017; accepted October 22, 2017; released online November 11, 2017 Time for primary review: 25 days

Department of Cardiac Surgery (K.Y., T.F., S.F., Y. Shimahara, Y.K., Y.M., N.K., J.K.), Department of Cardiovascular Medicine (T. Hitsumoto, N.I., Y.H., A.O., H.T., M.A., T. Hasegawa, Y. Sugano, H.K., T.A., S.Y.), National Cerebral and Cardiovascular Center, Suita, Japan

Mailing address: Tomoyuki Fujita, MD, PhD, Director, Department of Cardiac Surgery, National Cerebral and Cardiovascular Center, 5-7-1 Fujishirodai, Suita 565-8565, Japan. E-mail: tomofujita@nifty.com

ISSN-1346-9843 All rights are reserved to the Japanese Circulation Society. For permissions, please e-mail: cj@j-circ.or.jp 


\begin{tabular}{|c|c|c|c|}
\hline & Patient 1 & Patient 2 & Patient 3 \\
\hline Age at valve-in-valve (years) & 82 & 82 & 77 \\
\hline Sex & $\mathrm{F}$ & $\mathrm{F}$ & $\mathrm{F}$ \\
\hline $\mathrm{BSA}\left(\mathrm{m}^{2}\right)$ & 1.33 & 1.15 & 1.56 \\
\hline STS PROM (\%) & 6.7 & 5 & 4.4 \\
\hline Baseline NYHA class & II & II & II \\
\hline Prosthesis previously implanted & PERIMOUNT & Mosaic & PERIMOUNT \\
\hline Prosthesis true internal diameter & 17 & 15.5 & 17 \\
\hline Mode of degeneration & Stenosis & Stenosis and regurgitation & Stenosis \\
\hline Interval from SAVR (years) & 12.7 & 6.7 & 11.3 \\
\hline Baseline max aortic gradient (mmHg) & 72 & 98 & 96 \\
\hline Baseline mean aortic gradient $(\mathrm{mmHg})$ & 39 & 53 & 56 \\
\hline Baseline indexed effective orifice area $\left(\mathrm{cm}^{2} / \mathrm{m}^{2}\right)$ & 0.81 & 0.52 & 0.53 \\
\hline Baseline LVEF (\%) & 61 & 60 & 33 \\
\hline Valve area calculated by MDCT $\left(\mathrm{mm}^{2}\right)$ & 180.6 & 216.6 & 160.8 \\
\hline Perimeter calculated by MDCT (mm) & 49.5 & 53.0 & 45.8 \\
\hline Mean sinus of Valsalva height calculated by MDCT (mm) & 15.0 & 15.5 & 18.2 \\
\hline Mean sinus of Valsalva diameter calculated by MDCT $(\mathrm{mm})$ & 26.7 & 28.9 & 26.7 \\
\hline Left coronary ostia height calculated by MDCT (mm) & 9.6 & 9.5 & 9.5 \\
\hline Right coronary ostia height calculated by MDCT (mm) & 12.8 & 16.8 & 16.7 \\
\hline Most relevant risk factor & Porcelain aorta & Frailty & Impaired LV function \\
\hline Access for valve-in-valve & Transfemoral & Transfemoral & Transfemoral \\
\hline Transcatheter heart valve & SAPIEN XT & SAPIEN XT & SAPIEN XT \\
\hline Transcatheter heart valve size $(\mathrm{mm})$ & 20 & 23 & 23 \\
\hline Postprocedural max. aortic gradient $(\mathrm{mmHg})$ & 51 & 25 & 41 \\
\hline Postprocedural mean aortic gradient $(\mathrm{mmHg})$ & 35 & 16 & 29 \\
\hline Indexed effective orifice area $\left(\mathrm{cm}^{2} / \mathrm{m}^{2}\right)$ & 0.78 & 0.95 & 0.86 \\
\hline $\operatorname{LVEF}(\%)$ & 65 & 49 & 60 \\
\hline Oversizing ratio of THV-bioprosthesis (\%) & 74 & 108 & 158 \\
\hline Prosthetic valve regurgitation & None & None & None \\
\hline Paravalvular regurgitation & None & None & None \\
\hline Procedural complications & None & None & None \\
\hline Length of postoperative hospital stay (days) & 6 & 6 & 6 \\
\hline NYHA class at discharge & II & 1 & 1 \\
\hline
\end{tabular}

LVEF, left ventricular ejection fraction; MDCT, multidetector computed tomography; NYHA, New York Heart Association; SAVR, surgical aortic valve replacement; STS PROM, Society of Thoracic Surgeon Predicted Risk of Mortality.

valve via a transfemoral approach (Figure).

\section{Patient 2}

An 82-year-old woman presented with acute congestive cardiac failure caused by SVD of a $19-\mathrm{mm}$ Mosaic ${ }^{\mathrm{TM}}$ Bioprosthesis (Medtronic Inc., Corona, CA, USA) aortic valve, which had been implanted 6 years earlier, concomitant with implantation of a 25-mm Mosaic ${ }^{\mathrm{TM}}$ (Medtronic Inc.) mitral valve for severe aortic stenosis and severe mitral regurgitation. Echocardiography showed severe stenosis and moderate insufficiency of the aortic prosthetic valve and normal function of the mitral prosthetic valve. Surgical redo replacement was deferred because of the patient's frailty, but a 23-mm SAPIEN XT (Edwards Lifesciences) was successfully implanted over the previous bioprosthesis via a transfemoral approach (Figure).

\section{Patient 3}

A 77-year-old woman presented with progressive congestive cardiac failure caused by SVD of a 19-mm CarpentierEdwards PERIMOUNT Aortic Heart Valve (Edwards
Lifesciences), which had been implanted 11 years earlier to treat severe aortic stenosis associated with a bicuspid aortic valve. Echocardiography showed severe stenosis of the prosthetic valve, with global thickening and partial calcification of all 3 leaflets. Surgical redo replacement was deferred because of impaired left ventricular function, but a 23-mm SAPIEN XT (Edwards Lifesciences) was successfully implanted over the previously implanted valve via a transfemoral approach (Figure).

\section{Results}

There were no procedural complications. All patients recovered promptly. Echocardiography demonstrated a substantially reduced pressure gradient across the aortic valve, with no valvular insufficiency or paravalvular leakage in any patient. Patients were free of symptoms related to cardiac failure at the latest follow-up, which was on day 200, 110, and 123 in patients 1,2 , and 3, respectively. 


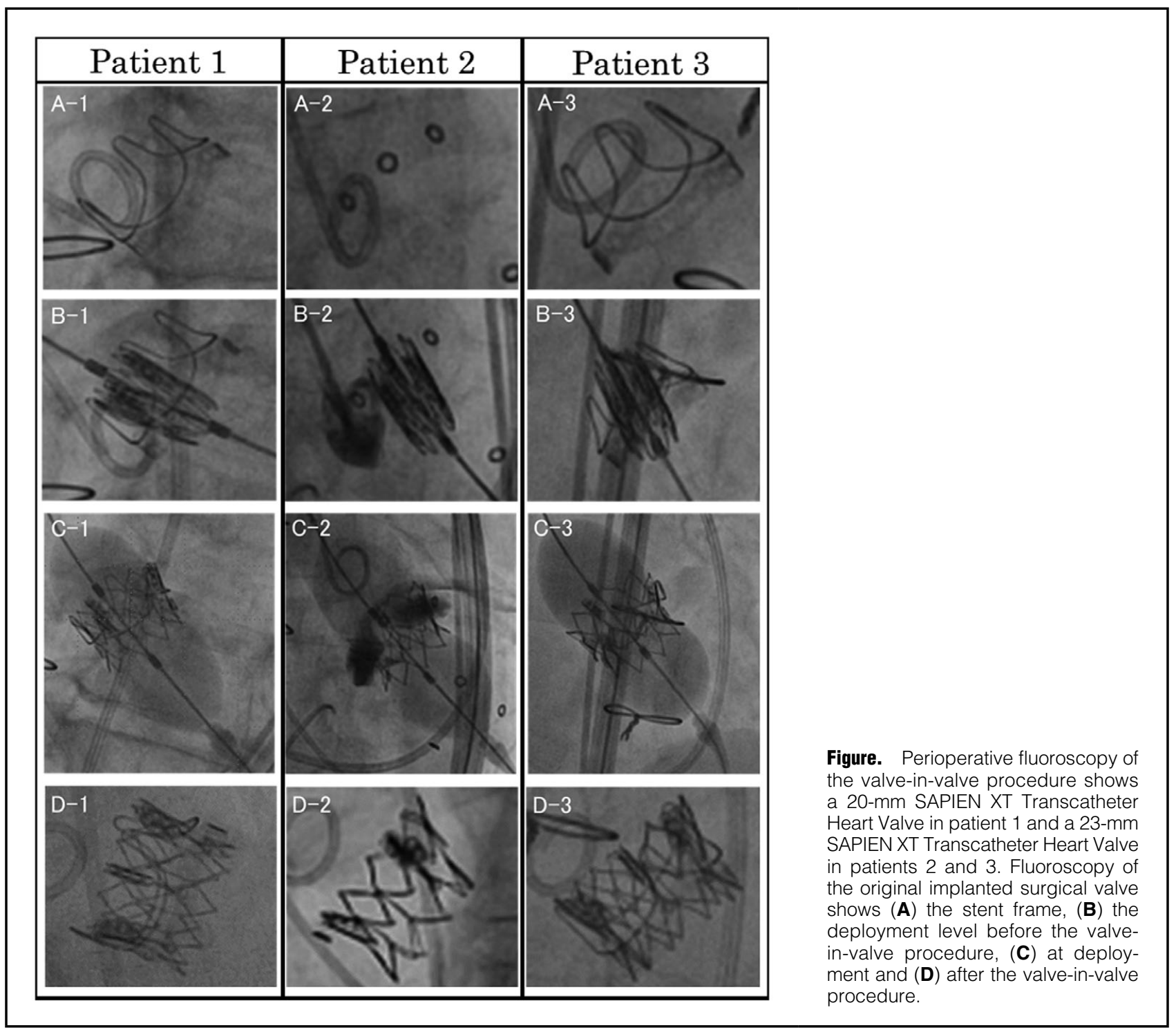

\section{Discussion}

The challenges in valve-in-valve treatment for a degenerated 19-mm bioprosthetic valve are optimization of the deployment position and the type and size of the THV. Dvir et $\mathrm{al}^{5}$ reported that, in valve-in-valve, the aortic pressure gradient is more reduced with a self-expanding device than with a balloon-expanding device. However, there was no significant difference in the 1-year mortality between the $2 \mathrm{THV}$ types.

More importantly, this procedure can lead to valve malposition or coronary obstruction. In particular, patients with a small surgical valve often have a small Valsalva sinus or a short coronary ostium, which should be considered when selecting the THV.9-12 The CoreValve Evolut R (Medtronic) for small, surgically treated valves should be carefully selected. ${ }^{13}$ Regarding the use of a balloonexpandable device, Bapat et al suggest that supra-annular implantation creates a cone-shaped THV with good functionality. ${ }^{9}$ To achieve appropriate deployment, the bottom level of THV implantation was deployed $<20 \%$ below the sewing ring of the surgical valve, as previously reported. ${ }^{9}$ Moreover, underexpansion of a balloon-expandable device in the valve-in-valve procedure for a small stented prosthesis would cause a residual gradient. ${ }^{14}$ To minimize residual aortic gradients after the valve-in-valve procedure for a small prosthesis, the 23-mm SAPIEN XT instead of the 20-mm SAPIEN XT was used for the latter 2 patients in the present cases and they showed a mean postprocedural gradient $<30 \mathrm{mmHg}$, which was not significantly different from those in the previous report. ${ }^{5}$ Severe prosthesis-patient mismatch (defined as EOAi $\leq 0.65 \mathrm{~cm}^{2} / \mathrm{m}^{2}$ ) is associated with death. ${ }^{15}$ In the present cases, the outer expansion of the 23-mm SAPIEN XT from the stent posts of the surgical valve (Figure C-2,C-3) was associated with better hemodynamics (obtained EOAi $0.86-0.95 \mathrm{~cm}^{2} / \mathrm{m}^{2}$ ) than with the normal shape created with the $20-\mathrm{mm}$ valve (Figure C-1), for which the EOAi was $0.78 \mathrm{~cm}^{2} / \mathrm{m}^{2}$. Thus, the type and size of the THV need to be selected according to the size and type of prosthesis and the native aortic root. Clinical follow-up with regular echocardiography is mandatory.

In conclusion, early outcomes demonstrated that the 
valve-in-valve procedure using a balloon-expanding THV was feasible, safe, and therapeutically effective in high-risk patients with a degenerated stented 19-mm aortic bioprosthetic valve.

\section{Disclosures}

Devices were provided without compensation by Edwards Lifesciences and Medtronic. T.F. is an advisor to Medtronic.

\section{References}

1. Nishimura RA, Otto CM, Bonow RO, Carabello BA, Erwin JP 3rd, Fleisher LA, et al. 2017 AHA/ACC Focused Update of the 2014 AHA/ACC Guideline for the Management of Patients With Valvular Heart Disease: A Report of the American College of Cardiology/American Heart Association Task Force on Clinical Practice Guidelines. Circulation 2017; 135: e1159-e1195.

2. Yamashita K, Fujita T, Hata H, Shimahara Y, Kume Y, Matsumoto Y, et al. Long-term outcome of isolated off-pump coronary artery bypass grafting in patients with coronary artery disease and mild to moderate aortic stenosis. J Cardiol 2017; 70: $48-54$.

3. Kirsch M, Nakashima K, Kubota S, Houël R, Hillion ML, Loisance $\mathrm{D}$. The risk of reoperative heart valve procedures in octogenarian patients. J Heart Valve Dis 2004; 13: 991-996.

4. Maganti M, Rao V, Armstrong S, Feindel CM, Scully HE, David TE. Redo valvular surgery in elderly patients. Ann Thorac Surg 2009; 87: $521-525$.

5. Dvir D, Webb JG, Bleiziffer S, Pasic M, Waksman R, Kodali S, et al. Transcatheter aortic valve implantation in failed bioprosthetic surgical valves. JAMA 2014; 312: 162-170.

6. Matsumoto Y, Fujita T, Hata H, Shimahara Y, Sato S, Kobayashi J. Hemodynamic performance and durability of mosaic bioprostheses for aortic valve replacement, up to 13 years. Circ J 2015; 79: 1044-1051.

7. Minakata K, Tanaka S, Okawa Y, Shimamoto M, Kaneko T, Takahara Y. Long-term outcome of the Carpentier-Edwards pericardial valve in the aortic position in Japanese patients. Circ J 2014; 78: 882-889.

8. Kappetein AP, Head SJ, Généreux P, Piazza N, van Mieghem $\mathrm{NM}$, Blackstone EH, et al. Updated standardized endpoint definitions for transcatheter aortic valve implantation: The Valve Academic Research Consortium-2 consensus document. J Am Coll Cardiol 2012; 60: 1438-1454.

9. Bapat V, Attia R, Redwood S, Hancock J, Wilson K, Young C, et al. Use of transcatheter heart valves for a valve-in-valve implantation in patients with degenerated aortic bioprosthesis: Technical considerations and results. J Thorac Cardiovasc Surg 2012; 144: 1372-1379.

10. Dvir D, Leipsic J, Blanke P, Ribeiro HB, Kornowski R, Pichard $\mathrm{A}$, et al. Coronary obstruction in transcatheter aortic valve-invalve implantation: Preprocedural evaluation, device selection, protection, and treatment. Circ Cardiovasc Interv 2015; 8: e002079.

11. Alnasser S, Cheema AN, Simonato M, Barbanti M, Edwards J, Kornowski R, et al. Matched comparison of self-expanding transcatheter heart valves for the treatment of failed aortic surgical bioprosthesis: Insights from the Valve-in-Valve International Data Registry (VIVID). Circ Cardiovasc Interv 2017; 10: e004392.

12. Webb JG, Mack MJ, White JM, Dvir D, Blanke P, Herrmann $\mathrm{HC}$, et al. Transcatheter aortic valve implantation within degenerated aortic surgical bioprostheses: PARTNER 2 valve-in-valve registry. J Am Coll Cardiol 2017; 69: 2253-2262.

13. Adamo M, Fiorina C, Curello S, Chizzola G, Pezzotti E, Gavazzi E, et al. Self-expanding transcatheter aortic valve implantation for degenerated small Mitroflow bioprosthesis: Early and midterm outcomes. EuroIntervention 2017; 13: e1032-e1039.

14. Gurvitch R, Cheung A, Ye J, Wood DA, Willson AB, Toggweiler $\mathrm{S}$, et al. Transcatheter valve-in-valve implantation for failed surgical bioprosthetic valves. J Am Coll Cardiol 2011; 58: $2196-$ 2209.

15. Zorn GL 3rd, Little SH, Tadros P, Deeb GM, Gleason TG, Heiser J, et al. Prosthesis-patient mismatch in high-risk patients with severe aortic stenosis: A randomized trial of a self-expanding prosthesis. J Thorac Cardiovasc Surg 2016; 151: 1014-1022, 1023.e1-e3. 